\title{
Educational differences in labor market marginalization among mature-aged working men: the contribution of early health behaviors, previous employment histories, and poor mental health
}

Emelie Thern ${ }^{1,2^{*}}$ (D) Jonas Landberg ${ }^{1,3}$ and Tomas Hemmingsson ${ }^{1,2}$

\begin{abstract}
Background: Social inequalities in labor force participation are well established, but the causes of these inequalities are not fully understood. The present study aims to investigate the association between educational qualification and labor market marginalization (LMM) among mature-aged working men and to examine to what extent the association can be explained by risk factors over the life course.

Method: The study was based on a cohort of men born between 1949 and 1951 who were examined for Swedish military service in 1969/70 and employed in $2000(n=41,685)$. Data on educational qualification was obtained in 2000 and information on the outcome of LMM (unemployment, sickness absence, and disability pension) was obtained between 2001 and 2008. Information on early health behaviors, cognitive ability, previous employment histories, and mental health was collected from conscription examinations and nationwide registers.

Results: Evidence of a graded association between years of education and LMM was found. In the crude model, compared to men with the highest level of education men with less than 12 years of schooling had more than a 2.5-fold increased risk of health-related LMM and more than a 1.5-fold increased risk of non-health-related LMM. Risk factors measured across the life course explained a large part of the association between education and health-related LMM (33-61\%) and non-health-related LMM (13-58\%).

Conclusions: Educational differences remained regarding LMM among mature-aged workers, even after considering several important risk factors measured across the life course. Previous health problems and disrupted employment histories explained the largest part of the associations.
\end{abstract}

Keywords: Social inequality, Education, Disability pension, Sickness absence, Unemployment, Labor-market marginalization, Mature-aged worker

\footnotetext{
* Correspondence: emelie.thern@su.se

'Department of Public Health Sciences, Stockholm University, 10691

Stockholm, Sweden

${ }^{2}$ Institute of Environmental Medicine, Karolinska Institute, Stockholm, Sweden

Full list of author information is available at the end of the article
}

C C The Author(s). 2020 Open Access This article is licensed under a Creative Commons Attribution 4.0 International License, which permits use, sharing, adaptation, distribution and reproduction in any medium or format, as long as you give appropriate credit to the original author(s) and the source, provide a link to the Creative Commons licence, and indicate if changes were made. The images or other third party material in this article are included in the article's Creative Commons. licence, unless indicated otherwise in a credit line to the material. If material is not included in the article's Creative Commons licence and your intended use is not permitted by statutory regulation or exceeds the permitted use, you will need to obtain permission directly from the copyright holder. To view a copy of this licence, visit http://creativecommons.org/licenses/by/4.0/. The Creative Commons Public Domain Dedication waiver (http://creativecommons.org/publicdomain/zero/1.0/) applies to the data made available in this article, unless otherwise stated in a credit line to the data. 


\section{Background}

Labor market marginalization (LMM), i.e. being more or less distant from the labor force due to sickness absence, unemployment or disability pension, among mature-aged workers ( 50 years or older) is becoming a notable public health and societal challenge, given that the majority of countries are becoming increasingly reliant upon the aging workforce [1]. Although Sweden has one of the highest participation rates of matured-aged workers in the labor force compared to other European countries, almost 20\% of the adults (55 to 64 years) were not active in the labor force in 2018 [2]. Mature-aged workers are vulnerable in the labor market as they might be forced to leave the labor force early due to health reasons or job loss; resulting in lower income, well-being, and life satisfaction [3-5]. Evidence suggests that individuals experiencing long-term sickness absence or job loss after the age of 45 face great difficulty returning to work or securing new adequate employment [6, 7]; consequently, LMM in this age group could be a strong risk factor for early permanent retirement. Furthermore, although the existence of social inequalities in labor force participation especially in older ages is well established [8-16], the causes of these inequalities are not fully understood. Thus, there is a need for an enhanced understanding of risk factors across the life course that could explain the social inequalities in labour force participation among mature-aged workers. Subsequently, to be able to target initiatives for sustaining employment up to and beyond retirement ages for the whole population, as this is vital for economic growth and sustainability [1].

The source of social inequalities in labor force participation could be differential exposure to various risk factors of LMM, such as an unequal distribution of poor health, lifestyle factors, and work-related factors [10-19]. The main body of previous research has focused on contemporary health, lifestyle habits, and work-related factors (i.e. heavy workload and poor psychosocial environment), and found that these factors do not sufficiently explain the social inequalities in labor force participation [10-19]. Only a few studies have investigated the contribution of factors measured before labor market entry $[16,18,19]$, which could be of importance as adolescence is a sensitive period during the life course when many health behaviors are established that could influence health later in life $[20,21]$. Previous research suggests that factors measured in late adolescence, especially IQ, explained a large part of the association between education and disability pension $[16,18,19]$. Furthermore, there has been less focus in the current literature on the risk factor of disrupted work histories over an extended period, which could be of importance as individuals with lower socioeconomic position (SEP) generally experience more sickness absence and unemployment during working life, and these factors appear to be major risk factors of later LMM [17, 22-25].

Thus, to get a better understanding of the underlying causes of the existing social inequalities in labor market participation, the present study aims to investigate the association between educational qualification and LMM among mature-aged working men and to examine to what extent the association can be explained by risk factors over the life course. For this purpose, we will use high-quality nation-wide registers and follow a large cohort of men who were enlisted in the Swedish military service in 1969/70.

\section{Method}

\section{Study population}

The study base included all men born between 1949 and 1951 who were examined for military service in 1969/ $1970(n=49,321)$ in Sweden. During this time military service was obligatory, by law, for all males aged 18-20 years. Only individuals with a severe handicap or congenital disorders were exempted from conscription, which was about 2 to $3 \%$ of the general population.

The study population for the current study included all men still alive and employed in 2000. Individuals that received disability pension before 2001 were excluded, as well as individuals with missing information on the level of education. Excluded participants had lower levels of educational qualification, lower IQ, more health risk behaviors during later adolescence, more disrupted work histories across their working life, and worse health during late adolescence, as well as later in life compared to the included participants (Table S1). The final analytical sample consisted of 41,685 men (Fig. 1).

\section{Exposure: educational qualification}

Information on the highest level of educational attainment, as a measure of SEP in middle age, was collected from the Longitudinal Register of Education and Labour Market Statistics (LISA) in 2000. The LISA-register was established in 1990, updated yearly by Statistics Sweden, and contains information on various factors related to education, income, and the labor market for all citizens from the age of 16 years [26]. The exposure variable of the highest level of education obtained was categorized into five separate groups based on the number of years in education: $\leq 9$ years (primary), $10-11$ years ( 2 years of upper secondary school), 12 years (3 years of upper secondary), $13-14$ years (2 years of university), and $\geq 15$ years (3 or more years of university), with the last group serving as the reference category. 


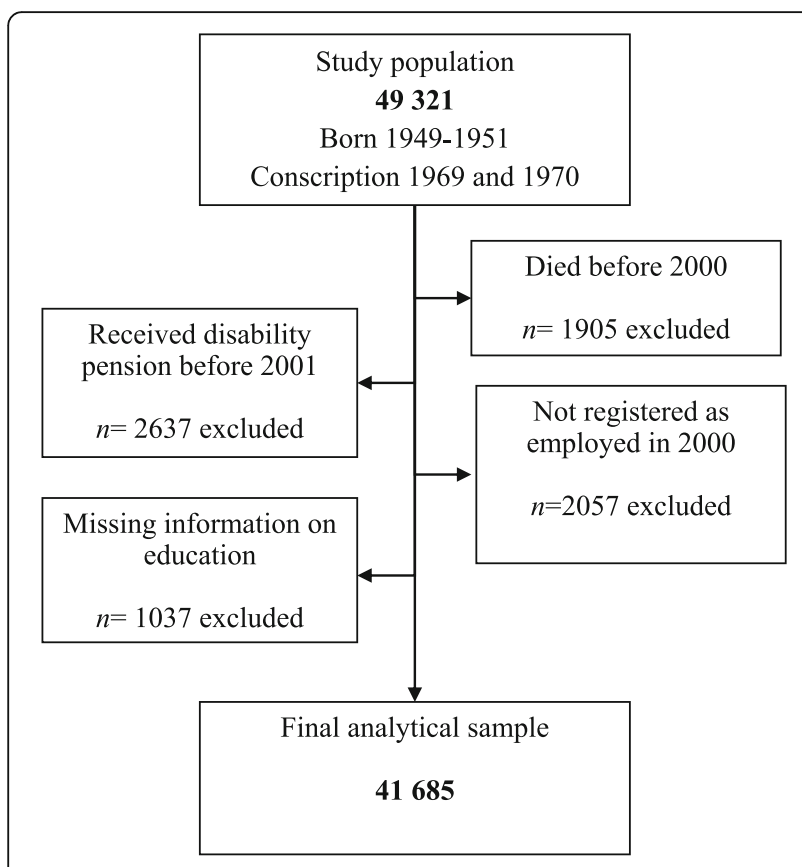

Fig. 1 Flow chart describing the selection process of the participants

\section{Outcome: labor market marginalization}

In line with previous research, the outcome of LMM was defined using three different measures: disability pension, long-term sickness absence, and long-term unemployment [27]. Information on the outcome was collected from the LISA-register from 1 January 2001 when the participants were 51-53 years old to 31 December 2008 when the participants were $57-59$ years old.

In Sweden, disability pension is granted to all citizens (irrespective of employment status) between the age of 19-64, who have a medically confirmed disease or injury that permanently impairs their work capacity by at least $25 \%$ [28]. In previous research, long-term sickness absence has been defined as receiving sickness benefits from the Swedish Social Insurance Agency for 90 days or more annually [27]. As we did not have available information on the number of days the individual was home on sick leave, an individual was considered being on long-term sickness absence if at least $25 \%$ of their yearly total income came from sickness benefits paid by the Swedish Social Insurance Agency. In line with previous research, longterm unemployment was defined as being registered as unemployed for at least 180 days in 1 year [27].

For the analyses, long-term sickness absence and disability pension were combined as one outcome, since sickness absence is a major risk factor for disability pension in this age-group $[17,23,24]$ and $90 \%$ of the individuals in the current sample who were granted disability pension during follow-up had received sickness benefits just before being granted disability pension. Thus, the two outcomes were health-related LMM (i.e. long-term sickness absence or disability pension) and non-health-related LMM (i.e. long-term unemployment).

\section{Covariates}

The selection and inclusion of individual- and family-level covariates were based on previous research [10, 16, 27]. Information on childhood SEP was obtained from the Swedish National Population and Housing Census 1960 when the participants were 9-11 years old. Childhood SEP was defined using the fathers' occupational class, which was categorized into seven groups according to the Swedish socioeconomic classification of occupations: (i) unskilled workers, (ii) skilled workers, (iii) low-level nonmanual employees, (iv) intermediate non-manual employees, (v) high-level non-manual employees, (vi) farmers, and (vii) those not classified into a socioeconomic group [29].

The Swedish military service conscription examinations consist of a standard medical assessment of physical and mental health, as well as two survey questionnaires. The questionnaires used at the conscription examinations have not been previously published, however, several previous studies have used information from the conscription examination as this data is available to researchers $[16,30]$. The following information was obtained from the conscription examination; IQ, smoking, alcohol consumption, body mass index (BMI), emotional control, and psychiatric and musculoskeletal diagnoses. The IQ test administered to the enlistees was based on four subtests designed to capture logical, spatial, verbal, and technical abilities [31]. From the four subtests, a global IQ score was calculated and standardized to give a Gaussian-distributed score between 1 and 9, with higher values indicating greater intellectual capacity. Health behaviors (i.e. smoking, alcohol, and BMI) were defined in line with previous research [16]. Participants smoking five cigarettes per day or more were considered as smokers. Risky use of alcohol was defined as consuming at least $250 \mathrm{~g}$ of $100 \%$ alcohol per week, using alcohol as an eye-opener, have been apprehended for drunkenness, or reported being drunk rather often or often. Height and weight were used to calculate BMI (weight/ height ${ }^{2}$ ). Participants with a BMI of $\geq 25$ at conscription were considered overweight. Low emotional control (rated by a psychologist) was defined as having lowstress tolerance and/or anxiety, reduced functioning due to psychosomatic symptoms, and uncontrollable nervousness, anxiousness, or aggression. All enlistees were examined by a physician and if considered necessary a psychiatrist. Psychiatric and musculoskeletal diagnoses were defined according to the International Classification of Diseases version 8 (ICD-8); codes 290 315 and $710-738$, respectively. 
Disrupted work histories were defined using three different measures of unemployment: youth unemployment, unemployed in young adulthood, and unemployed in middle adulthood. Youth unemployment was defined as experiencing more than 3 months of unemployment before the age of 18 and obtained from the conscription examination. Adapted from previous research [30], information from the Swedish Income and Tax Register on receiving unemployment benefits (Unemployment Insurance Funds) or unemployment assistance (Social Insurance Agency) was obtained between 1974 and 1991. Individuals receiving any benefit or assistance for at least 4 out of the 15 years were classified as been unemployed in young adulthood. Information on long-term unemployment between 1992 and 2000 was obtained from the LISA-register using the same definition as for the outcome variable. Participants were considered having experienced unemployment in middle adulthood if this was reported at least once between 1992 and 2000 .

Two measures of health-related factors were also included in the model; long-term sickness absence and receiving care for a psychiatric diagnosis. Information on long-term sickness absence was collected from 1990 to 2000 from the LISA register using the same definition as for the outcome, individuals were considered as been on long-term sickness absence if this was reported once between 1990 and 2000. Information on psychiatric diagnoses was obtained from the National Hospital Discharge Register between 1973 and 2000 (i.e. between the ages of 22-24 years and 50-52 years). Psychiatric diagnoses were defined by the following discharge diagnostic codes: ICD-8 and ICD-9: 290-315; ICD-10: F00-F99.

\section{Statistical analysis}

Pearson's chi-square tests $\left(\chi^{2}\right)$ were used to test for differences in baseline characteristics of the study population. The association between level of education and later LMM was estimated by Cox proportional hazard models to obtain hazard ratios (HR) with 95\% confidence intervals $(\mathrm{CI})$. The proportional hazards assumptions were tested using Schoenfeld residuals and found not to be violated (all $p$-values $\geq 0.05$ ). Information on the outcomes was obtained from registers that are updated annually; consequently, there was no exact date available for when the disability pension, sickness benefits, or unemployment benefits was received. Therefore, the day and month of the outcome were set on the 2nd of July as this is the middle of the year. Person-time was calculated from 1 January 2001 until the date of labor market marginalization, date of death, or until the end of follow-up (31 December 2008), whichever came first. The end of follow-up was set in 2008 due to register constraints.
Covariates were included individually as well as grouped according to a chronological timeline, we first included childhood SEP, then variables measured at conscription, then variables related to prior work histories, and finally health-related factors measured across the life course. In the final model, all variables were included simultaneously. Multicollinearity among the predictors was examined using the variance inflation factor (VIF); as all VIF values were below five, we determined that the potential issue of multicollinearity did not merit further investigation [32]. The percentage of $\mathrm{HR}$ reduction was calculated as $\left(\left(\mathrm{HR}_{\text {crude }}-\mathrm{HR}_{\text {adjusted }}\right) /\left(\mathrm{HR}_{\text {crude }}-1\right)\right) * 100$.

Additional analyses were conducted for the outcome of long-term unemployment, where individuals experiencing long-term sickness absence before the unemployment spell were excluded $(n=549)$, as long-term sickness absence could be a risk factor for later unemployment [17]. Furthermore, competing risk analyses in accordance with the method of Fine and Gray (1999) were conducted for both outcomes, including the date of death as a competing event, since the risk of death was not randomly distributed between the exposure groups. Missing values on covariates were coded as separate categories, as similar results were obtained when individuals with missing information on covariates were excluded (i.e. complete case analyses) (Table S2 and S3). All analyses were performed using Stata Statistical Software: Release 15.

\section{Results}

Baseline characteristics

The baseline characteristics of the study population, stratified by the highest level of educational qualification, can be found in Table 1. Those with lower levels of education had generally lower childhood SEP, lower IQ, more unhealthy habits during later adolescence, lower emotional control, and worse mental health in adolescence as well as later in life compared to individuals with higher levels of education. Individuals with higher levels of education had generally less disrupted work histories and fewer health problems compared to individuals with lower levels of education.

During follow-up, a total of 7713 (18.5\%) individuals were on long-term sick leave or received disability pension and 3526 (8.5\%) experienced long-term unemployment (Table 1). Follow-up time was on average 7 years for health-related LMM and 7.5 years for nonhealth-related LMM. During follow-up, a total of 1031individuals died, of which 302 (3.1\%) had the lowest level of education and $126(1.7 \%)$ had the highest level of education. The separate and unadjusted effects of all risk factors on health-related and non-health-related LMM are shown in Table 2. All risk factors included in 
Table 1 Baseline characteristics of study population, stratified by years of education

\begin{tabular}{|c|c|c|c|c|c|c|}
\hline \multirow[t]{2}{*}{ Total } & $\geq 15 \mathrm{n}(\%)$ & $13-14 n(\%)$ & $12 n(\%)$ & $10-11 \mathrm{n}(\%)$ & $\leq 9 \mathrm{n}(\%)$ & \multirow[t]{2}{*}{$p$-value } \\
\hline & $7327(15.6)$ & $6155(14.8)$ & $6664(16.0)$ & $11,915(28.6)$ & $9624(23.1)$ & \\
\hline \multicolumn{7}{|l|}{ Childhood SEP } \\
\hline Unskilled worker & $1311(17.9)$ & $1594(25.9)$ & $2023(30.4)$ & $4570(38.4)$ & $4144(43.1)$ & \multirow[t]{7}{*}{$<0.001$} \\
\hline Skilled worker & $1039(14.2)$ & $1265(20.6)$ & $1481(22.2)$ & $2998(25.2)$ & $2162(22.5)$ & \\
\hline Low-level non-manual employee & $1083(14.8)$ & $809(13.1)$ & $781(11.7)$ & $1019(8.6)$ & $586(6.1)$ & \\
\hline Intermediate non-manual employee & $2246(30.7)$ & $1366(22.2)$ & $1253(18.8)$ & 1415 (11.9) & $739(7.7)$ & \\
\hline High-level non-manual employee & $1054(14.4)$ & $347(5.6)$ & $361(5.4)$ & $261(2.2)$ & $170(1.8)$ & \\
\hline Farmer & $473(6.5)$ & $668(10.9)$ & $661(9.9)$ & $1362(11.4)$ & $1600(16.6)$ & \\
\hline Not classified & $121(1.7)$ & $106(1.7)$ & $104(1.6)$ & $290(2.4)$ & $223(2.3)$ & \\
\hline \multicolumn{7}{|l|}{$I Q^{b}$} \\
\hline High [7-9] & $5000(68.2)$ & $3369(54.7)$ & $2509(37.7)$ & $2058(17.3)$ & $867(9.0)$ & \multirow[t]{4}{*}{$<0.001$} \\
\hline Medium [4-6] & $2189(29.9)$ & $2559(41.6)$ & 3526 (52.9) & $7233(60.7)$ & $5133(53.3)$ & \\
\hline Low [1-3] & $130(1.8)$ & $220(3.6)$ & $622(9.3)$ & 2605 (21.9) & $3610(37.5)$ & \\
\hline Missing & $8(0.1)$ & $7(0.1)$ & $7(0.1)$ & $19(0.2)$ & $14(0.2)$ & \\
\hline \multicolumn{7}{|l|}{ Health behaviors ${ }^{\mathrm{b}}$} \\
\hline Smoking $\geq 5$ cigarettes/day & $2086(28.5)$ & $2167(35.2)$ & $2929(44.0)$ & $6183(51.9)$ & 5347 (55.6) & $<0.001$ \\
\hline Risky use of alcohol & $1027(14.0)$ & $909(14.8)$ & $1214(18.2)$ & $2775(23.3)$ & $2343(24.4)$ & $<0.001$ \\
\hline $\mathrm{BMI} \geq 25$ & $263(3.6)$ & $318(5.2)$ & $393(5.9)$ & $841(7.1)$ & $820(8.5)$ & $<0.001$ \\
\hline Low emotional control ${ }^{b}$ & $1753(23.9)$ & $1428(23.2)$ & $1616(24.3)$ & $3539(29.7)$ & $3294(34.2)$ & $<0.001$ \\
\hline Psychiatric diagnosis ${ }^{b}$ & $567(7.7)$ & $426(6.9)$ & $532(8.0)$ & $1360(11.4)$ & $1336(13.9)$ & $<0.001$ \\
\hline Musculoskeletal diagnosis $^{\mathrm{b}}$ & $1229(16.8)$ & $988(16.1)$ & $1013(15.2)$ & $1981(16.6)$ & $1698(17.6)$ & 0.001 \\
\hline \multicolumn{7}{|l|}{ Employment histories } \\
\hline Youth unemployment ${ }^{\mathrm{b}}$ & $205(2.8)$ & $261(4.2)$ & $402(6.0)$ & $1795(15.1)$ & $1898(19.7)$ & \multirow[t]{2}{*}{$<0.001$} \\
\hline Unemployed in young adulthood $^{c}$ & $210(2.9)$ & $241(3.9)$ & $231(3.5)$ & $992(8.3)$ & $484(5.0)$ & \\
\hline Unemployed in middle adulthood ${ }^{d}$ & $576(7.9)$ & $642(10.4)$ & $886(13.3)$ & $2341(19.7)$ & $1423(14.8)$ & $<0.001$ \\
\hline \multicolumn{7}{|l|}{ Health factors } \\
\hline Long-term sick leave & $447(6.5)$ & $607(9.9)$ & $962(14.4)$ & $2244(18.8)$ & $1918(19.9)$ & $<0.001$ \\
\hline Inpatient-care psychiatric diagnosis ${ }^{f}$ & $174(2.4)$ & $185(3.0)$ & $227(3.4)$ & $691(5.8)$ & $537(5.6)$ & $<0.001$ \\
\hline \multicolumn{7}{|l|}{ Outcome $^{g}$} \\
\hline Health-related LMM & $670(9.1)$ & $830(13.5)$ & $1130(17.0)$ & $2726(22.9)$ & $2357(24.5)$ & $<0.001$ \\
\hline Non-health-related LMM & $339(5.5)$ & $448(7.3)$ & $564(8.5)$ & $1295(10.9)$ & $820(8.5)$ & $<0.001$ \\
\hline
\end{tabular}

SEP Socioeconomic position, BMI Body mass index

${ }^{a}$ Measured in 1960

${ }^{\mathrm{b}}$ Measured during conscription in 1969

'Measured from 1974 to 1991

${ }^{\mathrm{d}}$ Measured from 1992 to 2000

e Measured from 1990 to 2000

${ }^{f}$ Measured from 1973 to 2000

${ }^{9}$ Measured between 2001 and 2008

the current study were positively associated with both outcomes, except for childhood SEP, BMI, and musculoskeletal diagnosis with non-health-related LMM.

\section{Education and health-related LMM}

As seen in Table 3, evidence of a graded association between years of education and health-related LMM was found. Individuals with a lower level of education had more than a 2.50-fold increased risk compared to individuals with the highest level of education in the crude analysis. Risk factors measured in childhood and during adolescence, as well as health-related factors, appeared to contribute to the largest reduction of the hazard ratios in the multivariable analysis. The largest attenuation of the association was found among individuals with lower levels of education. After including all potential risk factors, the increased risk found among all individuals with less than 15 years of education was reduced by 33 to $61 \%$. 
Table 2 Unadjusted HRs and 95\% Cls on the association between each potential risk factor and health-related LMM and nonhealth-related LMM (2001-2008)

\begin{tabular}{|c|c|c|}
\hline & $\begin{array}{l}\text { Health-related LMM } \\
(n=7713) \\
\text { HR }(95 \% \mathrm{Cl})\end{array}$ & $\begin{array}{l}\text { Non-health-related LMM } \\
(n=3526) \\
\text { HR }(95 \% \mathrm{Cl})\end{array}$ \\
\hline \multicolumn{3}{|l|}{ Childhood SEP } \\
\hline Unskilled worker & $1.65(1.46,1.87)$ & $1.09(0.93,1.28)$ \\
\hline Skilled worker & $1.60(1.41,1.81)$ & $1.07(0.91,1.26)$ \\
\hline Low-level non-manual employee & $1.23(1.07,1.41)$ & $0.98(0.82,1.17)$ \\
\hline Intermediate non-manual employee & $1.15(1.01,1.31)$ & $1.07(0.91,1.26)$ \\
\hline High-level non-manual employee (ref) & 1.00 & 1.00 \\
\hline Farmer & $1.71(1.49,1.95)$ & $0.73(0.61,0.88)$ \\
\hline \multicolumn{3}{|l|}{ IQ } \\
\hline High [7-9] (ref) & 1.00 & 1.00 \\
\hline Medium [4-6] & $1.67(1.58,1.77)$ & $1.25(1.15,1.35)$ \\
\hline Low [1-3] & $2.32(2.17,2.48)$ & $1.78(1.62,1.96)$ \\
\hline \multicolumn{3}{|l|}{ Health behaviors } \\
\hline Smoking & $1.43(1.37,1.50)$ & $1.31(1.23,1.41)$ \\
\hline Risky use of alcohol & $1.30(1.23,1.37)$ & $1.31(1.21,1.41)$ \\
\hline $\mathrm{BMI} \geq 25$ & $1.31(1.20,1.42)$ & $1.06(0.93,1.21)$ \\
\hline Low emotional control & $1.47(1.40,1.54)$ & $1.37(1.28,1.47)$ \\
\hline Psychiatric diagnosis & $1.64(1.54,1.74)$ & $1.56(1.42,1.72)$ \\
\hline Musculoskeletal diagnosis & $1.23(1.16,1.30)$ & $1.03(0.94,1.12)$ \\
\hline \multicolumn{3}{|l|}{ Employment histories } \\
\hline Youth unemployment & $1.49(1.40,1.59)$ & $1.58(1.44,1.73)$ \\
\hline Unemployed in young adulthood & $1.95(1.80,2.11)$ & $3.08(2.80,3.40)$ \\
\hline Unemployed in middle adulthood & $1.84(1.74,1.94)$ & $5.19(4.85,5.54)$ \\
\hline \multicolumn{3}{|l|}{ Health factors } \\
\hline Long-term sick leave & $4.97(4.75,5.21)$ & $1.76(1.63,1.91)$ \\
\hline Inpatient-care psychiatric diagnosis & $2.90(2.70,3.13)$ & $2.40(2.14,2.69)$ \\
\hline
\end{tabular}

LMM Labor market marginalization, BMI Body mass index

\section{Education and non-health-related LMM}

Table 4 shows the association between years of education and unemployment. Individuals with the lowest level of education had a slightly lower risk of long-term unemployment compared to the other groups in the multivariable analyses. Risk factors measured during childhood and late adolescence had a negligible effect on the risk estimates especially among individuals with at least 10 years of education. The largest attenuation of the risk estimates was found after including measures of disrupted work histories for all groups. Altogether, the risk factors attenuated the association between level of education and long-term unemployment by 13 to $58 \%$.

\section{Additional analyses}

Results from the additional analyses, when individuals with prior health-related LMM where excluded, demonstrated a similarly increased risk of non-health-related
LMM among individuals with lower levels of education as in the main analysis (Table S4). Similar results were obtained as in the main analyses when including the date of death as a competing event (Table S5 and S6).

\section{Discussion}

The results of this study suggest that educational differences in LMM among mature-aged men remain after considering several risk factors measured across the life course. Generally, disrupted employment histories and previous health problems explain the largest part of the association between education and LMM among mature-aged workers.

These results support and further extend the current literature on the social inequalities in LMM in several ways [8-16]. First, in concordance with earlier studies, we found that risk factors measured across the lifecourse seems to partly explain the increased risk of 
Table 3 Crude and adjusted hazard ratios (HRs) with 95\% confidence intervals (Cls) for the association between level of education (years) and health-related labor market marginalization among mature aged workers

\begin{tabular}{|c|c|c|c|c|c|}
\hline Adjustments & $\begin{array}{l}\geq 15 \\
\text { HR }(95 \% \mathrm{Cl})\end{array}$ & $\begin{array}{l}13-14 \\
\text { HR }(95 \% \mathrm{Cl})\end{array}$ & $\begin{array}{l}12 \\
\text { HR }(95 \% \mathrm{Cl})\end{array}$ & $\begin{array}{l}10-11 \\
\text { HR }(95 \% \mathrm{Cl})\end{array}$ & $\begin{array}{l}\leq 9 \\
\text { HR }(95 \% \mathrm{Cl})\end{array}$ \\
\hline Crude & 1.00 & $1.51(1.36,1.67)$ & $1.93(1.75,2.12)$ & $2.70(2.48,2.93)$ & $2.90(2.66,3.16)$ \\
\hline Childhood SEP (1960) & 1.00 & $1.47(1.33,1.63)$ & $1.88(1.70,2.07)$ & $2.58(2.36,2.81)$ & $2.75(2.51,3.00)$ \\
\hline IQ (1969) & 1.00 & $1.45(1.31,1.61)$ & $1.75(1.59,1.93)$ & $2.26(2.07,2.47)$ & $2.31(2.10,2.53)$ \\
\hline Health behaviors (1969) & 1.00 & $1.49(1.34,1.64)$ & $1.85(1.68,2.04)$ & $2.53(2.32,2.75)$ & $2.68(2.46,2.93)$ \\
\hline Low emotional control (1969) & 1.00 & $1.52(1.37,1.68)$ & $1.93(1.76,2.12)$ & $2.65(2.44,2.88)$ & $2.80(2.57,3.06)$ \\
\hline Psychiatric diagnosis (1969) & 1.00 & $1.52(1.37,1.68)$ & $1.93(1.75,2.12)$ & $2.66(2.44,2.89)$ & $2.82(2.59,3.07)$ \\
\hline Musculoskeletal diagnosis (1969) & 1.00 & $1.51(1.37,1.67)$ & $1.94(1.76,2.13)$ & $2.70(2.48,2.94)$ & $2.90(2.66,3.16)$ \\
\hline Adjusted for all above & 1.00 & $1.42(1.28,1.58)$ & $1.69(1.53,1.86)$ & $2.09(1.91,2.30)$ & $2.07(1.88,2.28)$ \\
\hline$\%$ reduction of $\mathrm{HR}$ & & $17 \%$ & $26 \%$ & $35 \%$ & $44 \%$ \\
\hline Youth unemployment (1969) & 1.00 & $1.51(1.36,1.67)$ & $1.92(1.74,2.11)$ & $2.63(2.41,2.86)$ & $2.80(2.57,3.05)$ \\
\hline Unemployed in young adulthood (1974-1991) & 1.00 & $1.50(1.35,1.66)$ & $1.92(1.75,2.12)$ & $2.60(2.39,2.83)$ & $2.86(2.62,3.11)$ \\
\hline Unemployed in middle adulthood (1992-2000) & 1.00 & $1.49(1.34,1.65)$ & $1.87(1.70,2.06)$ & $2.52(2.31,2.74)$ & $2.79(2.56,3.04)$ \\
\hline Adjusted for all unemployment variables & 1.00 & $1.48(1.34,1.64)$ & $1.86(1.69,2.05)$ & $2.43(2.23,2.64)$ & $2.70(2.48,2.95)$ \\
\hline$\%$ reduction of $\mathrm{HR}$ & & $6 \%$ & $7 \%$ & $16 \%$ & $10 \%$ \\
\hline Long-term sick leave (1990-2000) & 1.00 & $1.41(1.27,1.56)$ & $1.62(1.47,1.78)$ & $2.10(1.93,2.28)$ & $2.21(2.02,2.41)$ \\
\hline Mental diagnosis (1973-2000) & 1.00 & $1.50(1.35,1.66)$ & $1.91(1.73,2.10)$ & $2.59(2.38,2.82)$ & $2.78(2.55,3.03)$ \\
\hline Adjusted for all health-related variables & 1.00 & $1.41(1.27,1.56)$ & $1.62(1.47,1.78)$ & $2.06(1.90,2.25)$ & $2.19(2.00,2.38)$ \\
\hline$\%$ reduction of $\mathrm{HR}$ & & $19 \%$ & $33 \%$ & $37 \%$ & $38 \%$ \\
\hline Full model & 1.00 & $1.34(1.21,1.48)$ & $1.46(1.32,1.62)$ & $1.69(1.54,1.85)$ & $1.75(1.59,1.93)$ \\
\hline$\%$ reduction of $\mathrm{HR}$ & & $33 \%$ & $50 \%$ & $59 \%$ & $61 \%$ \\
\hline
\end{tabular}

SEP Socioeconomic position

LMM among individual with lower educational qualifications [10-19]. Extending previous research on social inequalities in labor market participation three measures of disrupted work histories during the life course were included, which was found to be one of the main risk factors of LMM and explain the largest part of the association between education and LMM. Previous research has found that prior unemployment is a major risk factor of LMM [17, 23-25], but less was known of how prior disrupted employment histories during the life course could explain the social inequalities in LMM. This is of great importance as individuals with fewer years of education reported prior unemployment spells in youth and during adulthood to a greater extent, suggesting that the individuals with lower SEP are more vulnerable on the labor market throughout working life which increases their risk of LMM later in life. In the current study, experiencing unemployment later in life appeared to explain a larger part of the association between education and non-health-related LMM among mature-aged workers compared to youth unemployment and unemployment in young adulthood among all groups. It should, however, be acknowledged that the information regarding prior unemployment during middle adulthood was collected during the 1990s, a period when Sweden was hit by an economic downturn; sickness absence and unemployment drastically increased during this time, from $1.7 \%$ in 1990 to $8.3 \%$ in 1993 [33]. Consequently, although some groups were hit harder (i.e. women, young adults, and immigrants), the unemployment experience during the economic crises was less influenced by health selection and more widespread to all sectors of the workforce [33]. To reduce this potential issue, we included several measures of unemployment outside of this period, as well as setting a high limit of unemployment days (i.e. unemployed at least 180 days) to define someone as unemployed during this period. Individuals excluded from the analytical sample reported lower levels of educational qualification and more disrupted work histories compared to the included individuals. Consequently, prior unemployment spells could potentially explain a larger part of the social inequalities in labor force participation.

Previous research has shown that prior sickness absence is a strong risk factor for later sickness absence and disability pensions [17, 23]. Extending these findings, our results showed that differences in prior sickness absence during the life course explained a large part of the association between educational qualification and health-related LMM. Furthermore, our results 
Table 4 Crude and adjusted hazard ratios (HRs) with 95\% confidence intervals (Cls) for the association between level of education (years) and non-health-related labor market marginalization among mature aged workers

\begin{tabular}{|c|c|c|c|c|c|}
\hline Adjustments & $\begin{array}{l}\geq 15 \\
\text { HR }(95 \% \mathrm{Cl})\end{array}$ & $\begin{array}{l}13-14 \\
\text { HR (95\%Cl) }\end{array}$ & $\begin{array}{l}12 \\
\text { HR (95\%Cl) }\end{array}$ & $\begin{array}{l}10-11 \\
\text { HR }(95 \% \mathrm{Cl})\end{array}$ & $\begin{array}{l}\leq 9 \\
\text { HR }(95 \% \mathrm{Cl})\end{array}$ \\
\hline Crude & 1.00 & $1.35(1.18,1.55)$ & $1.58(1.39,1.80)$ & $2.06(1.84,2.31)$ & $1.60(1.41,1.80)$ \\
\hline Childhood SEP (1960) & 1.00 & $1.41(1.23,1.61)$ & $1.65(1.45,1.88)$ & $2.19(1.95,2.46)$ & $1.74(1.54,1.97)$ \\
\hline IQ (1969) & 1.00 & $1.32(1.16,1.52)$ & $1.49(1.31,1.70)$ & $1.82(1.61,2.05)$ & $1.32(1.16,1.51)$ \\
\hline Health behaviors (1969) & 1.00 & $1.34(1.17,1.53)$ & $1.53(1.34,1.74)$ & $1.94(1.74,2.18)$ & $1.49(1.32,1.68)$ \\
\hline Low emotional control (1969) & 1.00 & $1.36(1.18,1.55)$ & $1.58(1.39,1.79)$ & $2.03(1.81,2.27)$ & $1.55(1.37,1.74)$ \\
\hline Psychiatric diagnosis (1969) & 1.00 & $1.36(1.18,1.55)$ & $1.58(1.39,1.79)$ & $2.03(1.81,2.27)$ & $1.55(1.38,1.75)$ \\
\hline Musculoskeletal diagnosis (1969) & 1.00 & $1.35(1.18,1.55)$ & $1.58(1.39,1.80)$ & $2.06(1.84,2.31)$ & $1.60(1.42,1.80)$ \\
\hline Adjusted for all above & 1.00 & $1.38(1.21,1.58)$ & $1.54(1.35,1.76)$ & $1.86(1.64,2.11)$ & $1.37(1.19,1.57)$ \\
\hline$\%$ reduction of $\mathrm{HR}$ & & $+9 \%$ & $7 \%$ & $18 \%$ & $39 \%$ \\
\hline Youth unemployment (1969) & 1.00 & $1.34(1.17,1.54)$ & $1.56(1.37,1.77)$ & $1.96(1.74,2.19)$ & $1.49(1.32,1.68)$ \\
\hline Unemployed in young adulthood (1974-1991) & 1.00 & $1.33(1.16,1.52)$ & $1.57(1.38,1.78)$ & $1.90(1.70,2.13)$ & $1.54(1.37,1.74)$ \\
\hline Unemployed in middle adulthood (1992-2000) & 1.00 & $1.27(1.11,1.45)$ & $1.38(1.21,1.56)$ & $1.56(1.39,1.75)$ & $1.34(1.19,1.51)$ \\
\hline Adjusted for all unemployment variables & 1.00 & $1.26(1.10,1.44)$ & $1.37(1.20,1.57)$ & $1.46(1.30,1.64)$ & $1.28(1.13,1.44)$ \\
\hline$\%$ reduction of $\mathrm{HR}$ & & $27 \%$ & $36 \%$ & $56 \%$ & $53 \%$ \\
\hline Long-term sick leave (1990-2000) & 1.00 & $1.33(1.16,1.52)$ & $1.51(1.33,1.71)$ & $1.92(1.71,2.15)$ & $1.47(1.31,1.66)$ \\
\hline Mental diagnosis (1973-2000) & 1.00 & $1.34(1.17,1.54)$ & $1.56(1.37,1.78)$ & $1.99(1.77,2.22)$ & $1.54(1.37,1.74)$ \\
\hline Adjusted for all health-related variables & 1.00 & $1.32(1.16,1.51)$ & $1.50(1.32,1.71)$ & $1.88(1.68,2.10)$ & $1.45(1.28,1.64)$ \\
\hline$\%$ reduction of $\mathrm{HR}$ & & $8 \%$ & $13 \%$ & $17 \%$ & $25 \%$ \\
\hline Full model & 1.00 & $1.30(1.14,1.49)$ & $1.39(1.21,1.59)$ & $1.46(1.28,1.65)$ & $1.25(1.09,1.43)$ \\
\hline$\%$ reduction of $\mathrm{HR}$ & & $13 \%$ & $33 \%$ & $57 \%$ & $58 \%$ \\
\hline
\end{tabular}

SEP Socioeconomic position

suggest that receiving a psychiatric diagnosis, in late adolescence or later in life, explained very little of the association between educational qualification and LMM, which is in line with similar previous research [16]. Other research, where the focus has not been on educational differences, has found that childhood and adult psychological health problems and worse general health were positively associated with unemployment, permanent sickness, and early exit later in life [34, 35]. Workers, and especially mature-aged workers, are a selected group with better health compared to same-aged individuals outside of the labor force. This became evident in the exclusion analysis, whereas mental health problems were more prevalent among the excluded participants compared to the included participants $(4.4 \%$ compared to $27.8 \%$ ). In Sweden, the two most common underlying diagnoses for sickness absence or being granted disability pension are musculoskeletal diagnoses and mental disorders [36]. Unfortunately, we did not have access to information on the underlying diagnoses of the sickness absence or disability pension in the current study; thus, we are unable to examine the primary reason for the health-related LMM.

Previous research on social inequalities in disability pension has found that factors measured in late adolescence, especially IQ, explained the largest part of the association $[16,18,19]$. This was also found in the current study, when long-term sickness absence was also included in the outcome, among the men with the lowest level of education and in relation to health-related LMM. IQ and educational qualification appear to be strongly linked as previous research suggest that low IQ is an important predictor for unsuccessful educational achievement at age 30 [37]. Even though IQ and education are highly correlated they can still act as moderators for each other in relation to health outcomes [38, 39]; for example, cognitive ability is an independent predictor of long-term sickness absence [40]. We found that health behaviors measured during adolescence contributed little in explaining the educational differences found concerning LMM. Previous research has found that health behaviors measured during adolescence contribute little to explaining the socioeconomic differences in all-cause disability pension, though they explain a large part of the differences concerning disability pension due to an alcohol disorder [16, 19]. Even though adolescence can be considered a sensitive period where most health behaviors are initiated and established, many of the health behaviors included in the study could have 
changed [21], especially considering the major changes that have occurred in population lifestyles [41]. Subsequently, including a measure of current health behaviors might have resulted in larger attenuations of the risk estimates among the individuals with lower levels of education, which has been seen in previous research on social inequalities in sickness absence where current obesity and smoking status explained a large part of the association [10]. On the other hand, previous research on smoking trajectories from adolescence to later adulthood has found a positive association between smoking during adolescence and later unemployment irrespective of later smoking status [42].

It should also be recognized that the Swedish social insurance system went through some changes during the follow-up period of the current study, which could have influenced the results. The disability pension system was moved from the pension system to the social security system in 2003 , following a name change to disability benefit to reinforce the perception that receiving this benefit was not a permanent exit from the labor market, which it had previously been [28]. The calculation of payments was also changed but the eligibility criterion remained the same. Furthermore, the Swedish government wanted to halve the number of individuals being granted sickness compensation and disability benefits by the year 2008, which resulted in a drastic decrease in the number of newly granted disability beneficiaries [43]. Previous research suggests that changes in a social system, such as applying a stricter criteria for eligibility of disability pension or increasing the retirement age, often result in a change in the occurrence of using alternative exit routes from the labor market, such as disability pension, unemployment benefits or early retirement, especially among individuals with poor health [12, 44, 45]. Since we included such a wide definition of LMM, we would most likely capture the individuals forced to use an alternative route to disability pension and thus this reform should not have too much influence on the current result.

To achieve the sustainability developmental goals concerning population aging, it has been suggested that governments should gradually increase the official retirement age, which Sweden and many other countries are currently trying to implement [1]. The results of this study and previous research suggest that this might increase the health inequalities among the older populations as opportunities to be able to extend working life might be dependent on SEP $[9,15]$. Taking a life-course perspective to gain a better understanding of the determinants and reasons for leaving the labor market early, especially among those with lower levels of education and income, is important in promoting more stable work participation.
Around $24 \%$ of the current study population experienced LMM at a mature age and only around half returned to the workforce during follow-up (data not shown), suggesting that being marginalized from the workforce after the age of 50 could be a strong risk factor for an early permanent exit from the labor force. Mature aged workers are vulnerable on the labor market and face great difficulty returning to the labor force in case of sickness absence or unemployment; thus, measures need to be taken much earlier to ensure participation in the labor force is made possible for all older workers $[6,7]$.

\section{Strengths and limitations}

Conducting a register derived study following a large cohort of men with a long-term follow-up is a major strength. Also, linking nation-wide registers to the rich data source of the conscription cohort with selfreported data on several health measures and health behaviors allowed us to include information on several important risk factors across the life course. Unfortunately, risk factors such as health behaviors were only measured in late adolescence and have most likely changed during the life course; thus, these measures are most likely not an accurate representation of health behaviors among mature-aged men. The information from the conscription was not collected retrospectively, minimizing the issue of recall bias. An obvious shortcoming of the conscription cohort is that it only includes men. Previous research has found the association between education and earlier exit from the labor market due to disability pension is quite similar among males and females, though perhaps somewhat steeper for males, even though females are overrepresented among disability beneficiaries [18]. In the current study, we found that disrupted work histories were an important factor for males, which could be of interest to further investigate for females who often have more disrupted work histories due to childcare.

The risk of self-report bias and attrition was decreased by collecting information on the exposure and outcome from high-quality registers. Using the highest level of educational qualification as an indicator of SEP could be a potential limitation, as it might lose discriminatory power with old age; however, due to register constraints, we were unable to include another common indicator of SEP such as occupational class. Concerning the outcome, we did not have an exact date when the individual was marginalized from the labor force. This limitation in the register should not have influenced the main results as we choose a date mid-year to censor individuals in the analysis and there is most likely no seasonal variation in the number of individuals being on sick-leave, unemployed, or granted disability pension. Furthermore, 
the amount of unemployment, sickness absence, and disability pension benefits received depend on your salary (less than $80 \%$ of your salary), but there is an upper limit to how much money one can receive each day. Consequently, high-income earners will be given the maximum benefit allowed regardless of their actual income which means that there could be some misclassification with regards to long-term sick leave as the definition was based on calculating a percentage of sickness benefit received in relation to income.

A strength was the ability to include several measures of previous unemployment spells, as these factors appear to be of importance. However, a limitation is that we were unable to include any information on the work environment with regards to physical workload and psychosocial environment which appear to be important determinates of disability pension and early retirement [13, 46]. Manual workers, who often have lower levels of education, have more adverse physical work environments which increases their risk of early retirement due to health issues.

\section{Conclusion}

Lower levels of educational qualification increased the risk of being marginalized from the workforce after the age of 50 years, even after considering several risk factors measured across the life course. Bearing in mind the ambition to increase the statutory retirement age in many countries, it is important to study determinants of LMM and an early exit from the labor market especially among individuals with low SEP to be able to lengthen labor force participation in the whole population.

\section{Supplementary Information}

The online version contains supplementary material available at https://doi. org/10.1186/s12889-020-09899-5.

Additional file 1: Supplementary Table 1. Baseline characteristics of the individuals included and excluded in the study population. Supplementary Table 2. Complete case analysis excluding 1908 individuals with missing information on covariates, crude and adjusted hazard ratios (HRs) with 95\% confidence intervals (Cls) for the association between educational qualification and health-related labor market marginalization among mature-aged workers. Supplementary Table 3 Complete case analysis excluding 1908 individuals with missing information on covariates, crude and adjusted hazard ratios (HRs) with 95\% confidence intervals (Cls) for the association between educational qualification and non-health-related labor market marginalization among mature-aged workers. Supplementary Table 4: Additional analyses excluding 549 individuals that experienced long-term sickness absence prior to long-term unemployment, crude and adjusted hazard ratios (HRs) with 95\% confidence intervals $(\mathrm{Cls})$ for the association between educational qualification and non-health-related labor market marginalization among mature aged workers. Supplementary Table 5. Competing risk regression for the association between level of education (years) and health-related labor market marginalization among mature aged workers, with death as competing risk. Supplementary Table $\mathbf{6}$. Competing risk regression for the association between level of education (years) and non-health-related labor market marginalization among mature aged workers, with death as competing risk.

\section{Abbreviations}

LMM: Labor Market Marginalization; LISA : Longitudinal Register of Education and Labour Market Statistics; SEP: Socioeconomic position; BMI: Body mass index

\section{Acknowledgments}

Not applicable.

\section{Authors' contributions}

$\mathrm{TH}$ conceived the study in collaboration with ET and JL. TH and JL worked with the acquisition of the data. ET performed the initial analyses in collaboration with $J \mathrm{~L}$ and TH. ET drafted the initial version of the manuscript. $J L$ and $T H$ helped review drafts of the manuscript. All authors read and approved the final manuscript.

\section{Funding}

This project has been funded by grants to Tomas Hemmingsson from the Swedish Research Council for Health, Working Life and Welfare (FORTE) (Dnr: 2016-17185) and The Swedish Research Council (Dnr: 2018-01917). The funders had no role or influence over study design, data collection, analysis, interpretation of the data, manuscript writing, or the decision to publish the results. Open Access funding provided by Stockholm University.

\section{Availability of data and materials}

The data that support the findings of this study are available from Statistics Sweden but restrictions apply to the availability of these data, which were used under license for the current study, and so are not publicly available. Data are however available from the authors upon reasonable request and with permission of Statistics Sweden.

\section{Ethics approval and consent to participate}

The study was approved by the Stockholm Regional Ethical Review Board at Karolinska Institute (no. 2010/604-32). The review board deemed it was not necessary to obtain informed consent for participation in the study.

\section{Consent for publication}

Not applicable.

\section{Competing interests}

The authors declare that they have no competing interests.

\section{Author details}

${ }^{1}$ Department of Public Health Sciences, Stockholm University, 10691 Stockholm, Sweden. ${ }^{2}$ Institute of Environmental Medicine, Karolinska Institute, Stockholm, Sweden. ${ }^{3}$ Department of Clinical Neuroscience, Karolinska Institute, Stockholm, Sweden.

Received: 18 June 2020 Accepted: 16 November 2020

Published online: 25 November 2020

References

1. United Nations DoEaSA. Population Division. New York: World Population Ageing 2019; 2020.

2. Short-Term Labour Market Statsitics: Inactivity Rates [Internet]. Organisation for Economic Co-operation and Development 2020 [cited Feburary 18, 2020]. Available from: https://stats.oecd.org/Index.aspx?DataSetCode=STLABOUR\#.

3. Hetschko C, Knabe A, Schöb R. Looking Back in anger? Retirement and Unemployment Scarring. Demography. 2019;56(3):1105-29.

4. Barrett GF, Kecmanovic M. Changes in subjective well-being with retirement: assessing savings adequacy. Appl Econ. 2013;45(35):4883-93.

5. Gong $\mathrm{CH}$, Kendig H. Impacts of voluntary and involuntary workforce transitions at mature ages: longitudinal evidence from HILDA. Australas J Ageing. 2018;37(1):11-6.

6. Madsen AÅ. Return to work after first incidence of long-term sickness absence: a 10-year prospective follow-up study identifying labour-market trajectories using sequence analysis. Scand J Public Health. 2020;48(2):13443.

7. Chan S, Huff SA. Job loss and employment patterns of older workers. J Labor Econ. 2001;19(2):484-521. 
8. Robroek SJ, Nieboer D, Järvholm B, Burdorf A. Educational differences in duration of working life and loss of paid employment: working life expectancy in The Netherlands. Scand J Public Health. 2020;46(1):77-84.

9. Carr E, Fleischmann M, Goldberg M, Kuh D, Murray ET, Stafford M, et al. Occupational and educational inequalities in exit from employment at older ages: evidence from seven prospective cohorts. Occup Environ Med. 2018; 75(5):369-77.

10. Kaikkonen R, Härkänen T, Rahkonen O, Gould R, Koskinen S. Explaining educational differences in sickness absence: a population-based follow-up study. Scand J Work Environ Health. 2015;41(4):338-46.

11. Nilsen SM, Ernstsen L, Krokstad S, Westin S. Educational inequalities in disability pensioning-the impact of illness and occupational, psychosocial, and behavioural factors: the Nord-Trøndelag health study (HUNT). Scand J Public Health. 2012;40(2):133-41.

12. Leinonen $\mathrm{T}$, Pietiläinen $\mathrm{O}$, Laaksonen $\mathrm{M}$, Rahkonen $\mathrm{O}$, Lahelma $\mathrm{E}$, Martikainen P. Occupational social class and disability retirement among municipal employees - the contribution of health behaviors and working conditions. Scand J Work Environ Health. 2011;37(6):464-72.

13. Polvinen A, Gould R, Lahelma E, Martikainen P. Socioeconomic differences in disability retirement in Finland: the contribution of ill-health, health behaviours and working conditions. Scand J Public Health. 2013;41(5):470-8.

14. Schuring M, Robroek SJ, Otten FW, Arts CH, Burdorf A. The effect of ill health and socioeconomic status on labor force exit and re-employment: a prospective study with ten years follow-up in the Netherlands. Scand J Work Environ Health. 2013;39(2):134-43.

15. Schuring M, Schram JL, Robroek S, Burdorf A. The contribution of health to educational inequalities in exit from paid employment in five European regions. Scand J Work Environ Health. 2019;45(4):346-55.

16. Johansson E, Leijon O, Falkstedt D, Farah A, Hemmingsson T. Educational differences in disability pension among Swedish middle-aged men: role of factors in late adolescence and work characteristics in adulthood. J Epidemiol Community Health. 2012;66(10):901-7.

17. Hultin H, Lindholm C, Möller J. Is there an association between long-term sick leave and disability pension and unemployment beyond the effect of health status?-a cohort study. PLoS One. 2012;7(4):e35614.

18. Falkstedt $D$, Backhans $M$, Lundin A, Allebeck $P$, Hemmingsson T. Do working conditions explain the increased risks of disability pension among men and women with low education? A follow-up of Swedish cohorts. Scand J Work Environ Health. 2014;40(5):483-92.

19. Upmark M, Lundberg I, Sadigh J, Bigert C. Conditions during childhood and adolescence as explanations of social class differences in disability pension among young men. Scand J Public Health. 2001;29(2):96-103.

20. Kuh D, Ben-Shlomo Y, Lynch J, Hallqvist J, Power C. Life course epidemiology. J Epidemiol Community Health. 2003:57(10):778.

21. Viner RM, Ross D, Hardy R, Kuh D, Power C, Johnson A, et al. Life course epidemiology: recognising the importance of adolescence. J Epidemiol Community Health. 2015;jech-2014:205300.

22. Gjesdal S, Ringdal PR, Haug K, Mæland JG. Predictors of disability pension in long-term sickness absence: results from a population-based and prospective study in Norway 1994-1999. Eur J Pub Health. 2004;14(4):398-405.

23. Salonen L, Blomgren J, Laaksonen M, Niemelä M. Sickness absence as a predictor of disability retirement in different occupational classes: a registerbased study of a working-age cohort in Finland in 2007-2014. BMJ Open. 2018;8(5):e020491.

24. Arulampalam W, Gregg P, Gregory M. Unemployment scarring. Econ J. 2001; 111(475):577-84.

25. Helgesson M, Johansson B, Nordqvist T, Lundberg I, Vingård E. Unemployment at a young age and later unemployment in native Swedish and immigrant young adults. Mod Econ. 2014;5(01):24.

26. Ludvigsson JF, Svedberg P, Olén O, Bruze G, Neovius M. The longitudinal integrated database for health insurance and labour market studies (LISA) and its use in medical research. Eur J Epidemiol. 2019;34(4):423-37.

27. Helgesson M, Tinghög P, Niederkrotenthaler T, Saboonchi F, MittendorferRutz E. Labour-market marginalisation after mental disorders among young natives and immigrants living in Sweden. BMC Public Health. 2017:17(1):593.

28. Lindwall U. Changes in social security and welfare contributions 1986-01-01 to 2015-09-01 (in Swedish: Förändringar inom socialförsäkrings - och bidragsområderna 1968-01-01--2015-09-01). Stockholm: Försäkringskassan; 2015.

29. Sweden S. Socio-economic classification (in Swedish: Socioekonomisk indlening (SEI)). Örebro: SCB; 1982.
30. Lundin A, Hemmingsson T. Adolescent predictors of unemployment and disability pension across the life course-a longitudinal study of selection in 49321 Swedish men Uppsala, Sweden Institutet for evaluation of labour market and education policy; 2013.

31. David AS, Malmberg A, Brandt L, Allebeck P, Lewis G. IQ and risk for schizophrenia: a population-based cohort study. Psychol Med. 1997;27(6):1311-23.

32. Yoo W, Mayberry R, Bae S, Singh K, He QP, Lillard JW Jr. A study of effects of multicollinearity in the multivariable analysis. Int J Appl Sci Technol. 2014; 4(5):9.

33. Bergmark $\AA$, Palme J. Welfare and the unemployment crisis: Sweden in the 1990s. Int J Soc Welf. 2003;12(2):108-22.

34. Clark C, Smuk M, Lain D, Stansfeld S, Carr E, Head J, et al. Impact of childhood and adulthood psychological health on labour force participation and exit in later life. Psychol Med. 2017;47(9):1597-608.

35. Van Rijn RM, Robroek SJ, Brouwer S, Burdorf A. Influence of poor health on exit from paid employment: a systematic review. Occup Environ Med. 2014; 71(4):295-301.

36. Swedish Social Insurance Agency. Sickness absence 2016 (In Swedish: Sjukfrånvarons utveckling 2016). 2016. Report No.: 7.

37. Hegelund ER, Flensborg-Madsen T, Dammeyer J, Mortensen EL. Low IQ as a predictor of unsuccessful educational and occupational achievement: a register-based study of 1,098,742 men in Denmark 1968-2016. Intelligence. 2018;71:46-53.

38. Batty GD, Deary IJ, Macintyre S. Childhood IQ in relation to risk factors for premature mortality in middle-aged persons: the Aberdeen children of the 1950s study. J Epidemiol Community Health. 2007;61(3):241-7.

39. Deary IJ, Johnson W. Intelligence and education: causal perceptions drive analytic processes and therefore conclusions. Int J Epidemiol. 2010;39(5): 1362-9.

40. Henderson J, Gray R, Brocklehurst P. Systematic review of effects of lowmoderate prenatal alcohol exposure on pregnancy outcome. BJOG. 2007; 114(3):243-52.

41. Public Health Agency of Sweden. Öppna jämförelser folkhälsa 2019 (In Swedish: Open public health comparisions). Stockholm: Public Health Agency of Sweden; 2019.

42. Brook JS, Zhang C, Burke L, Brook DW. Trajectories of cigarette smoking from adolescence to adulthood as predictors of unemployment status. Nicotine Tob Res. 2014;16(12):1559-66.

43. Regeringen. Letter of regulation for the, financial year concerning the Swedish National Insurance Agency (In Swedish: Regleringsbrev för budgetåret 2003 avseende Riksförsäkringsverket). Stockholm: Ministry of Social Affairs; 2003. p. 2002

44. Kadefors R, Nilsson K, Östergren P-O, Rylander L, Albin M. Social inequality in working life expectancy in Sweden. Z Gerontol Geriatr. 2019;52(1):52-61.

45. Karlström A, Palme M, Svensson I. The employment effect of stricter rules for eligibility for Dl: evidence from a natural experiment in Sweden. J Public Econ. 2008;92(10-11):2071-82.

46. Browne P, Carr E, Fleischmann M, Xue B, Stansfeld SA. The relationship between workplace psychosocial environment and retirement intentions and actual retirement: a systematic review. Eur J Ageing. 2019;16(1):73-82.

\section{Publisher's Note}

Springer Nature remains neutral with regard to jurisdictional claims in published maps and institutional affiliations.

Ready to submit your research? Choose BMC and benefit from:

- fast, convenient online submission

- thorough peer review by experienced researchers in your field

- rapid publication on acceptance

- support for research data, including large and complex data types

- gold Open Access which fosters wider collaboration and increased citations

- maximum visibility for your research: over $100 \mathrm{M}$ website views per year

At BMC, research is always in progress.

Learn more biomedcentral.com/submission 